International Journal of Physical Research, $7(2)(2019) 48-60$
International Journal of Physical Research
SPC
Website: www.sciencepubco.com/index.php/IJPR
Research paper

\title{
Empirical models for predicting global solar radiation using meteorological parameters for Sokoto, Nigeria
}

\author{
Davidson O. Akpootu ${ }^{1 *}$, Bello I. Tijjani², Usman M. Gana² \\ ${ }^{1}$ Department of Physics, Usmanu Danfodiyo University, Sokoto, Nigeria \\ ${ }^{2}$ Department of Physics, Bayero University, Kano, Nigeria \\ *Corresponding authorE-mail:davidson.odafe@udusok.edu.ng
}

\begin{abstract}
The performances of sunshine, temperature and multivariate models for the estimation of global solar radiation for Sokoto (Latitude $13.02^{\circ} \mathrm{N}$, Longitude $05.25^{\circ} \mathrm{E}$ and $350.8 \mathrm{~m}$ asl) located in the Sahelian region in Nigeria were evaluated using measured monthly average daily global solar radiation, maximum and minimum temperatures, sunshine hours, rainfall, wind speed, cloud cover and relative humidity meteorological data during the period of thirty one years (1980-2010). The comparison assessment of the models was carried out using statistical indices of coefficient of determination $\left(\mathrm{R}^{2}\right)$, Mean Bias Error (MBE), Root Mean Square Error (RMSE), Mean Percentage Error (MPE), $\mathrm{t}$ - test, Nash - Sutcliffe Equation (NSE) and Index of Agreement (IA). For the sunshine based models, a total of ten (10) models were developed, nine (9) existing and one author's sunshine based model. For the temperature based models, a total of four (4) models were developed, three (3) existing and one author's temperature based model. The results of the existing and newly developed author's sunshine and temperature based models were compared and the best empirical model was identified and recommended. The results indicated that the author's quadratic sunshine based model involving the latitude and the exponent temperature based models are found more suitable for global solar radiation estimation in Sokoto. The evaluated existing Ångström type sunshine based model for the location was compared with those available in literature from other studies and was found more suitable for estimating global solar radiation. Comparing the most suitable sunshine and temperature based models revealed that the temperature based models is more appropriate in the location. The developed multivariate regression models are found suitable as evaluation depends on the available combination of the meteorological parameters based on two to six variable correlations. The recommended models are found suitable for estimating global solar radiation in Sokoto and regions with similar climatic information with higher accuracy and climatic variability.
\end{abstract}

Keywords: Global Solar Radiation; Multivariate Models; Sokoto; Sunshine Based Model; Temperature Based Models.

\section{Introduction}

Solar radiation is the energy transferred from the sun in the form of radiant to the earth's surface or it is simply the electromagnetic radiation emitted from the Sun. The most important parameter used in the design and evaluation of solar energy devices is the solar radiation. The sun through the emission of solar radiation provides about $99.97 \%$ of the heat energy required for physical processes [1]. The importance of solar radiation goes beyond its uses in everyday life; it is the primary source which allows existence of life on Earth. Along with its important role for existence, many human and environmental processes rely on the Sun's energy for natural development. Examples of these processes include the evaporation of water which leads to precipitation, the photochemical processes involved with crop growth and the control of climatological conditions on Earth [2-3].

The traditional way to ascertain the amount of global solar radiation (GSR) in a particular region is to install pyranometers at as many locations as possible in this region thus requiring daily maintenance and data recording, and consequently increasing cost of GSR data collection. Thus, it is rather more economical to develop methods to estimate the GSR using climatological parameters [4]. Technical know-how for measuring solar radiation is costly and has instrumental hazards [5]. Therefore, alternative methods for estimating these data are required. One of these methods is the use of empirical models. Accurate modeling depends on the quality and quantity of the measured data used, and is a good tool for generating solar radiation at locations where measured data are not available [6].

Evidently, the best and most reliable information on solar radiation is that obtained from experimental measurements of the global and diffuse components of the solar insolation at the location in question. Regrettably, there are few meteorological stations conducting such measurements in developing countries such as Nigeria, this could be attributed to (i) inability to afford the measuring equipment due to the cost and (ii) lack of trained personnel to handle the measurement. Therefore, it is rather important to develop models to estimate the solar radiation using the available weather parameters.

Several models have been proposed to estimate global solar radiation. Ångström [7] was the first scientist known to suggest a simple linear relationship to estimate global solar radiation. Page [8] presents a linear regression model used in correlating the global solar radiation data with relative sunshine duration, which is a modified Ångström type model. Tijjani [9] determined a set of constants for Ång- 
ström - type correlation of the first and second order to estimate the monthly average daily global solar radiation for Katsina using five years (2005 - 2009) data of measured monthly global solar radiation and sunshine hours obtained from the Meteorological Department of the Federal Airport Authority of Nigeria (FAAN). According to him, the second order performed better than the first order based on the coefficient of correlation with 0.702 and 0.345 respectively. Muhammad and Darma [10] employed the monthly mean minimum/maximum temperature and relative humidity data obtained from Nigerian Meteorological Agency (NIMET), Abuja-Nigeria during the period of 6 years $(2005$ - 2010) to estimate the monthly average daily global solar radiation on a horizontal surface for Kano, Nigeria using modified Ångström models from which models were developed with regression coefficients a and b of (1.2577 - 1.0167$)$ and $(0.8317-0.0043)$ based on temperature ratio and relative humidity.

Olatona and Adeleke [11] developed some simple empirical models for the prediction of monthly mean daily solar radiation on a horizontal surface for Ibadan from sunshine hours and minimum and maximum temperatures data obtained from International Institute of Tropical Agriculture (IITA) Meteorological station at Ibadan, the data obtained covered a period of twenty years (1992 - 2011). Their results showed that the sunshine hour has lower mean errors than those based on minimum and maximum temperature which consistently produced an overestimation. Abdu and Abdullateef [12] used monthly mean data of sunshine hours obtained from the Nigerian Meteorological Agency (NIMET), Oshodi-Lagos, Nigeria during the period of 6 years (2009 - 2014) to estimate the global solar radiation for Zaria based on Angstom - Prescott type model. The Ångström coefficients "a" and "b" obtained in their study are 0.3325 and 0.4510 . The MBE and RMSE were also evaluated. Argungu and Dabai [13] compared linear and multivariate regression models for the estimation of global solar radiation in Sokoto, Nigeria using meteorological data of sunshine hours, relative humidity, minimum and maximum temperatures for a period of six years (2007 - 2012) obtained from the Nigerian Meteorological Agency (NIMET), Oshodi-Lagos, Nigeria. According to them, the best result was achieved using the model that combined sunshine hours, temperatures and natural logarithms of relative humidity. Girma [14] compare several existing sunshine and temperature based models using data on sunshine hours, minimum and maximum temperatures obtained from the Ethiopian Institute of Agricultural Research: Tepi National Spices Research Centre to estimate the global solar radiation for Tepi located in South West of Ethiopia. The monthly averages sunshine hour for 4 years (2013 2016) and monthly averages maximum and minimum temperatures for 5 years (2012 - 2016). The monthly averages daily global solar radiation from the Archives of National Aeronautics and Space Administration (NASA) for 22 years (July, 1983 - June, 2005 ) was utilized in his study. According to him, from the sunshine based models, the Samuel (polynomial) and the Newland (logarithm) models are appropriate for Tepi while the Chen et al model from the temperature based models is more appropriate for Tepi.

The purpose of this study is to develop new sunshine and temperature dependent models for estimating global solar radiation for Sokoto, Nigeria and to compare these developed models with existing models in literature to ascertain which of these models reliably estimate global solar radiation in the location under investigation. The evaluated existing Ångström type sunshine based model was also compared with those available in literature. Multivariate based models were also developed for the study area.

\section{Methodology}

\subsection{Acquisition of data}

It has been reported according to the World Meteorological Organization [15] and Ojo and Adeyemi [16] that to ensure the optimal climate modeling, data series should extend to at least thirty years long. In this regard, the measured monthly average daily global solar radiation, maximum and minimum temperatures, sunshine hours, rainfall, wind speed, cloud cover and relative humidity meteorological data during the period of thirty one years (1980-2010) was utilized in this study. The meteorological data were obtained from the Nigerian Meteorological Agency (NIMET), Oshodi, Lagos, Nigeria. Twenty five (25) years $(1980-2004)$ data was used for developing the empirical models while six (6) years $(2005-2010)$ data was used for the models validation.

\subsection{Regression analysis}

The first correlation proposed for estimating the monthly average global solar radiation is based on the method of Ångström [7]. The original Ångström- Prescott type regression equation relating monthly average daily radiation to clear day radiation in a given location and average fraction of possible sunshine hours is given by the equation:

$$
\frac{\mathrm{H}}{\mathrm{H}_{\mathrm{o}}}=\mathrm{a}_{1}+\mathrm{b}_{1}\left(\frac{\mathrm{s}}{\mathrm{S}_{\mathrm{o}}}\right)
$$

where $\mathrm{H}$ is the monthly average daily global solar radiation on a horizontal surface $\left(\mathrm{MJ} / \mathrm{m}^{2} / \mathrm{day}\right), \mathrm{H}_{\mathrm{o}}$ is the monthly average daily extraterrestrial radiation on a horizontal surface $\left(\mathrm{MJ} / \mathrm{m}^{2} /\right.$ day), $\mathrm{S}$ is the monthly average daily hours of bright sunshine, $\mathrm{S}_{\mathrm{o}}$ is the monthly average day length and $a_{1}$ and $b_{1}$ values are the Ångström empirical constants. The monthly average daily extraterrestrial radiation on a horizontal surface $\left(\mathrm{H}_{\mathrm{o}}\right)$ can be calculated for days giving average of each month from the following equation [17 - 18]:

$$
\mathrm{H}_{\mathrm{o}}=\left(\frac{24}{\pi}\right) \mathrm{I}_{\mathrm{sc}}\left[1+0.033 \cos \left(\frac{360 \mathrm{n}}{365}\right)\right]\left[\cos \varphi \cos \delta \sin \omega_{\mathrm{s}}+\left(\frac{2 \pi \omega_{\mathrm{s}}}{360}\right) \sin \varphi \sin \delta\right]
$$

where $\mathrm{I}_{\mathrm{sc}}$ is the solar constant $\left(=1367 \mathrm{Wm}^{-2}\right), \varphi$ is the latitude of the site, $\delta$ is the solar declination and $\omega_{\mathrm{s}}$ is the mean sunrise hour angle for the given month and $\mathrm{n}$ is the number of days of the year starting from $1^{\text {st }}$ of January to $31^{\text {st }}$ of December.

The solar declination, $\delta$ and the mean sunrise hour angle, $\omega_{\mathrm{s}}$ can be calculated using the following equation [17 - 18]:

$$
\begin{gathered}
\delta=23.45 \sin \left\{360\left(\frac{284+\mathrm{n}}{365}\right)\right\} \\
\omega_{\mathrm{s}}=\cos ^{-1}(-\tan \varphi \tan \delta)
\end{gathered}
$$

For a given month, the maximum possible sunshine duration (monthly average day length $\left(\mathrm{S}_{\mathrm{o}}\right)$ ) in hours can be computed [17 - 18] by 


$$
\mathrm{S}_{\mathrm{o}}=\frac{2}{15} \omega_{\mathrm{s}}
$$

The clearness index $\left(\mathrm{K}_{\mathrm{T}}\right)$ is defined as the ratio of the observed/measured horizontal terrestrial solar radiation $\mathrm{H}$, to the calculated/predicted/estimated horizontal extraterrestrial solar radiation $\mathrm{H}_{\mathrm{o}}[19]$.

$$
\mathrm{K}_{\mathrm{T}}=\frac{\mathrm{H}}{\mathrm{H}_{\mathrm{o}}}
$$

In this study, $\mathrm{H}_{\mathrm{o}}$ and $\mathrm{S}_{\mathrm{o}}$ was computed for each month using equations (2) and (5) respectively.

Table 1: Sunshine Based Regression Models Proposed in the Literature that was adopted in this Study

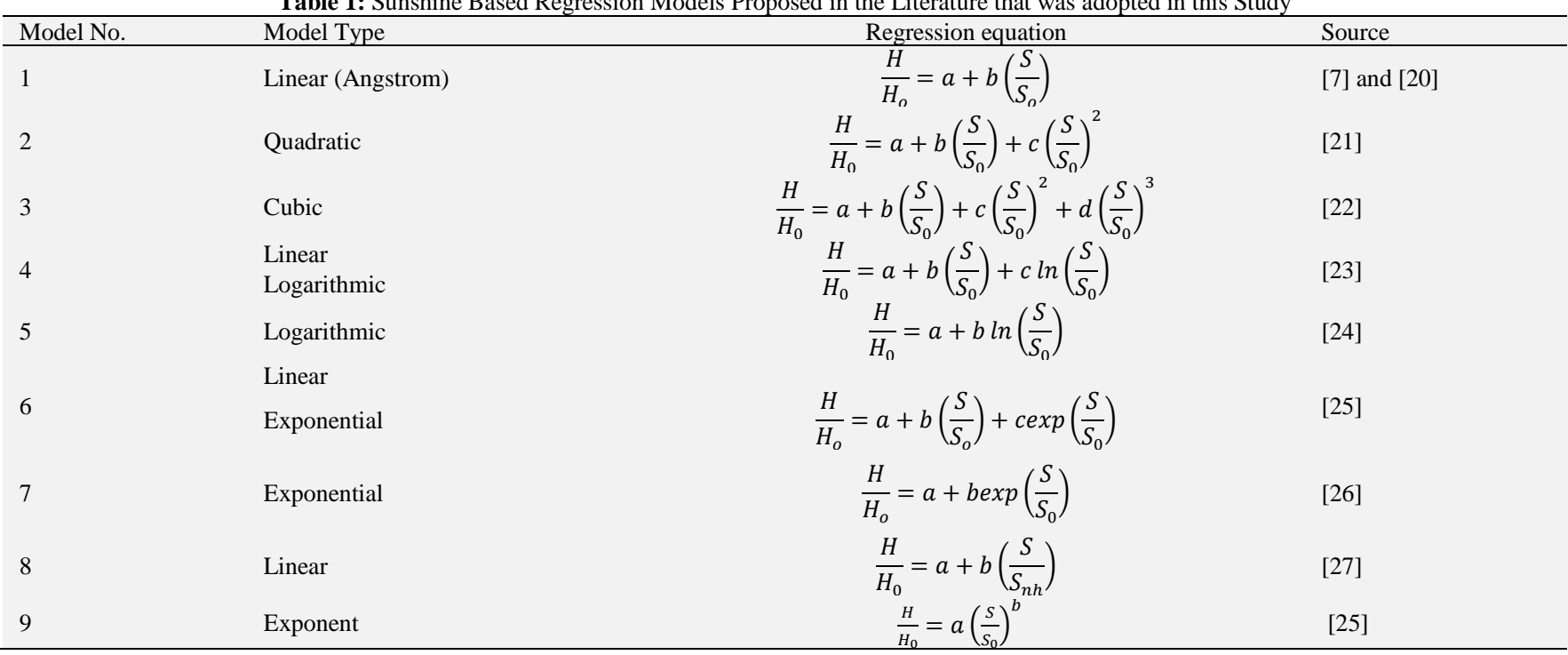

Model 8 is a modification of the Angström-Prescott model through the use of the ratio of $\left(\frac{S}{S_{n h}}\right)$ instead of $\left(\frac{S}{S_{0}}\right)$ by Louche et al. [27] and $\left(\frac{S}{S_{n h}}\right)$ is given by the relation: $\frac{1}{S_{n h}}=\frac{0.8706}{S_{0}}+0.0003$

The proposed sunshine based model by the authors in this study is shown on Table 2

Table 2: Sunshine Based Regression Model Proposed in this Study

\begin{tabular}{lllc}
\hline Model No. & Model Type & Regression equation & Source \\
\hline 10 & Quadratic, latitude related & $\frac{H}{H_{0}}=a+b \cos \varphi\left(\frac{S}{S_{0}}\right)+\cos \varphi\left(\frac{S}{S_{0}}\right)^{2}$ & Authors \\
\hline
\end{tabular}

Table 3: Temperature Based Regression Models Proposed in Literature that was adopted in this Study

\begin{tabular}{llc}
\hline Model No. & Model Type & Regression equation \\
\hline 1 & Logarithmic & $\frac{H}{H_{0}}=a_{2}+b_{2} \ln \Delta T$ \\
2 & Linear exponent & $\frac{H}{H_{0}}=a_{3}+b_{3} \Delta T^{0.5}$ \\
3 & Linear & $\frac{H}{H_{0}}=a_{4}+b_{4}\left(\frac{\Delta T}{S_{0}}\right)$ \\
\hline
\end{tabular}

where $H, H_{0}$ and $S_{0}$ are as previously defined. $\Delta T$ is the difference between the monthly average daily maximum and minimum temperatures, i.e., $T_{\max }-T_{\min }$

The constants $a_{2,}, a_{3}, a_{4}, b_{2}, b_{3}$ and $b_{4}$ in Table 3 are empirical coefficients determined by regression techniques and are also known as the regression coefficients and the other terms are the correlated parameters. The models are the three widely used temperature based models and are appropriate for different climatic conditions.

The proposed temperature based model by the authors in this study is given in Table 4 .

Table 4: Temperature Based Regression Model Proposed in this Study

\begin{tabular}{llcc}
\hline Model No. & Model Type & Regression equation & Source \\
\hline 4 & Exponent & $\frac{H}{H_{0}}=a\left[\left(\frac{\Delta T}{S_{0}}\right)\right]^{b}$ & Authors \\
\hline
\end{tabular}

The models in Table 2 and 4 are proposed for this study in form of mathematical equations that relate the clearness index as the dependent variable with sunshine hour and temperature as the independent variables, also, are the multivariate models for other parameters. The proposed sunshine and temperature based models are simply a modification of the Ogelma et al and Garcia existing models. The essence of modification is to find out if it improves the accuracy of the existing models through modification.

The accuracy or validation of the estimated values was statistically tested by computing the MBE, RMSE, MPE, t-test, NSE and the IA, similarly, $R^{2}$ was determined for each of the models. The expressions for the MBE, RMSE and MPE as stated according to El-Sebaii and Trabea [31] are given as follows. 


$$
\begin{aligned}
& M B E=\frac{1}{n} \sum_{i=1}^{n}\left(H_{i, \text { cal }}-H_{i, \text { mea }}\right) \\
& R M S E=\left[\frac{1}{n} \sum_{i=1}^{n}\left(H_{i, \text { cal }}-H_{i, \text { mea }}\right)^{2}\right]^{\frac{1}{2}} \\
& M P E=\frac{1}{n} \sum_{i=1}^{n}\left(\frac{H_{i, \text { mea }}-H_{i, \text { cal }}}{H_{i, \text { mea }}}\right) * 100
\end{aligned}
$$

The t-test defined by student [32] in one of the tests for mean values, the random variable $t$ with $n-1$ degrees of freedom may be written as follows.

$$
t=\left[\frac{(n-1)(M B E)^{2}}{(R M S E)^{2}-(M B E)^{2}}\right]^{\frac{1}{2}}
$$

The Nash-Sutcliffe equation (NSE) is given by the expression

$$
N S E=1-\frac{\sum_{1}^{n}\left(H_{i, \text { mea }}-H_{i, c a l}\right)^{2}}{\sum_{1}^{n}\left(H_{i, \text { mea }}-\bar{H}_{i, \text { meas }}\right)^{2}}
$$

The Index of Agreement (IA) is given as

$$
I A=1-\frac{\sum_{i=1}^{n}\left(H_{i, c a l}-H_{i, \text { mea }}\right)^{2}}{\sum_{i=1}^{n}\left(\left|H_{i, c a l}-\bar{H}_{i, \text { mea }}\right|+\left|H_{i, \text { mea }}-\bar{H}_{i, \text { mea }}\right|\right)^{2}}
$$

From equations (7) - (12) $H_{i, m e a}, H_{i, c a l}$ and $n$ are respectively the $i^{\text {th }}$ measured and $i^{\text {th }}$ calculated values of daily global solar radiation and the total number of observations, also $\bar{H}_{i, \text { mea }}$ is the mean measured global radiation.

Chen et al. [28] have recommended that a zero value for MBE is ideal and a low RMSE and MPE are desirable. The smaller the value of the MBE, MPE and RMSE the better is the model's performance, a positive MPE and MBE values provide the averages amount of overestimation in the calculated values, while the negative values gives underestimation. The percentage error between $-10 \%$ and $+10 \%$ is considered acceptable [33]. The smaller the value of $t$ the better is the performance. High value of $\mathrm{R}^{2}$, NSE and IA are desirable. The MBE and the RMSE are in $\mathrm{MJm}^{-2} \mathrm{day}^{-1}$, while $\mathrm{R}^{2}$, MPE, NSE and IA are in percentage (\%), the $\mathrm{t}$ - test is non dimensional.

Multiple linear regression equation for estimating the global solar radiation with the clearness index been the dependent variable and the six independent meteorological variables is given as

$$
\frac{H}{H_{0}}=a+b x_{1}+c x_{2}+d x_{3}+e x_{4}+f x_{5}+g x_{6}
$$

where $a \ldots \ldots . . g$ are the regression coefficients and $x_{1} \ldots \ldots x_{6}$ are the correlated parameters.

The number of ways of combining the meteorological variables was obtained using the equation

$$
n_{C_{r}}=\frac{n !}{(n-r) ! r !}
$$

where $n$ is the total number of meteorological variables under study and $r$ is the number of meteorological variables to be combined. In this study, the best five from the two, three and four variable regression equations and the best three from the five variable regression equations based on coefficient of determination was selected for further statistical analysis.

\section{Results and discussion}

\subsection{Sunshine based models for Sokoto}

The evaluated regression equation for the existing sunshine based models for Sokoto based on Table 1 are

$$
\begin{aligned}
& \frac{H}{H_{0}}=0.0749+0.809 \frac{S}{S_{0}} \\
& \frac{H}{H_{0}}=-0.655+3.05 \frac{S}{S_{0}}-1.71\left(\frac{S}{S_{0}}\right)^{2} \\
& \frac{H}{H_{0}}=1.09-5.1 \frac{S}{S_{0}}+10.9\left(\frac{S}{S_{0}}\right)^{2}-6.5\left(\frac{S}{S_{0}}\right)^{3} \\
& \frac{H}{H_{0}}=2.05-1.30 \frac{S}{S_{0}}+1.38 \ln \left(\frac{S}{S_{0}}\right) \\
& \frac{H}{H_{0}}=0.832+0.530 \ln \left(\frac{S}{S_{0}}\right) \\
& \frac{H}{H_{0}}=1.26+4.27 \frac{S}{S_{0}}-1.79 \exp \left(\frac{S}{S_{0}}\right)
\end{aligned}
$$




$$
\begin{aligned}
\frac{H}{H_{0}} & =-0.199+0.416 \exp \left(\frac{S}{S_{0}}\right) \\
\frac{H}{H_{0}} & =0.0741+0.927 \frac{S}{S n h} \\
\frac{H}{H_{0}} & =0.882\left(\frac{S}{S_{0}}\right)^{0.893}
\end{aligned}
$$

The evaluated regression equation for the authors proposed sunshine based model for Sokoto based on Table 2 is

$$
\frac{H}{H_{0}}=-0.655+3.13 \cos \varphi\left(\frac{S}{S_{0}}\right)-1.75 \cos \varphi\left(\frac{S}{S_{0}}\right)^{2}
$$

\begin{tabular}{|c|c|c|c|c|c|c|c|c|}
\hline Models & $\mathrm{R}^{2}$ & MBE & RMSE & MPE & $\mathrm{t}$ & NSE & IA & Total Rank \\
\hline Eqn.15a & 5 & 1 & 7 & 5 & 1 & 7 & 7 & 33 \\
\hline Eqn. $15 b$ & 2 & 8 & 3 & 8 & 8 & 3 & 4 & 36 \\
\hline Eqn.15c & 1 & 10 & 10 & 10 & 10 & 10 & 10 & 61 \\
\hline Eqn. $15 d$ & 3 & 9 & 4 & 9 & 9 & 4 & 1 & 39 \\
\hline Eqn.15e & 4 & 4 & 5 & 7 & 4 & 5 & 5 & 34 \\
\hline Eqn.15f & 2 & 7 & 1 & 3 & 7 & 1 & 3 & 24 \\
\hline Eqn.15g & 6 & 6 & 9 & 1 & 6 & 1 & 9 & 38 \\
\hline Eqn. $15 \mathrm{~h}$ & 5 & 3 & 8 & 6 & 3 & 9 & 8 & 42 \\
\hline Author's Models & $\mathrm{R}^{2}$ & MBE & RMSE & MPE & $\mathrm{t}$ & NSE & IA & Total Rank \\
\hline Eqn. $15 \mathrm{j}$ & 2 & 5 & 2 & 2 & 5 & 2 & 2 & 20 \\
\hline
\end{tabular}

Table 5: A) Validation of the Sunshine Based Models for Sokoto under Different Statistical Test

\begin{tabular}{lllllll}
\hline Models & $\mathrm{R}^{2}$ & MBE & RMSE & MPE & $\mathrm{t}$ & IA \\
\hline Eqn.15a & 83.6 & 0.0093 & 0.8645 & -0.1954 & 0.0357 & 97.4425 \\
Eqn.15b & 85.1 & -0.0950 & 0.8346 & 0.3393 & 0.3801 & 97.6168 \\
Eqn.15c & 85.2 & -0.4647 & 0.9499 & 2.0761 & 1.8605 & 96.9127 \\
Eqn.15d & 85.0 & 0.1103 & 0.8403 & -0.6304 & 0.4393 & 97.5840 \\
Eqn.15e & 84.5 & 0.0196 & 0.8439 & -0.2272 & 0.0769 & 97.5633 \\
Eqn.15f & 85.1 & -0.0370 & 0.8302 & 0.0660 & 0.1481 & 97.6416 \\
Eqn.15g & 82.8 & -0.0335 & 0.8836 & -0.0035 & 0.1257 & 97.6416 \\
Eqn.15h & 83.6 & 0.0130 & 0.8652 & -0.2125 & 0.0497 & 97.4384 \\
Eqn.15i & 83.6 & -0.0129 & 0.8619 & -0.0863 & 0.0495 & 97.4010 \\
Author's Model & $\mathrm{R}^{2}$ & MBE & RMSE & MPE & t & 99.3835 \\
Eqn.15j & 85.1 & -0.0301 & 0.8303 & 0.0329 & 0.1202 & NSE \\
\hline
\end{tabular}

Table 5: B) Ranking of the Evaluated Sunshine Based Models for Sokoto as Per Statistical Test

Table 5A) and 5B) gives the summary of the various statistical tests adopted and ranking of the sunshine based models for Sokoto. Based on the $\mathrm{R}^{2}$ the model, equation $15 \mathrm{c}$ (existing model) has the highest value with $85.2 \%$ and is judged the best model, while the model, equation $15 \mathrm{~g}$ (existing model) has the lowest value with $82.8 \%$. Based on the MBE, the model, equation 15a (existing model) has the lowest value with overestimation of $0.0093 \mathrm{MJm}^{-2} \mathrm{day}^{-1}$ in the estimated value and is judged the best model, while the model, equation $15 \mathrm{c}$ (existing model) has the highest value with underestimation of $0.4697 \mathrm{MJm}^{-2} \mathrm{day}^{-1}$ in the estimated value. Based on the RMSE the model, equation $15 \mathrm{f}$ (existing model) has the lowest value with $0.8302 \mathrm{MJm}^{-2} \mathrm{day}^{-1}$ and is judged the best model, while the model, equation 15c (existing model) has the highest value with $0.9499 \mathrm{MJm}^{-2} \mathrm{day}^{-1}$. Based on the MPE, despite the observed overestimation and underestimation exhibited by some of the existing and researcher's models they all fall within the acceptable range $(M P E \leq \pm 10 \%)$ with the model, equation $15 \mathrm{~g}$ (existing model) having the lowest value with underestimation of $0.0035 \%$ in the estimated value and is judged the best model, while the model, equation 15c (existing model) has the highest value with overestimation of $2.0761 \%$ in the estimated value. The study site was statistically tested at the $(1-\alpha)$ confidence levels of significance of $95 \%$ and $99 \%$. For the critical t-value, i.e., at $\alpha$ level of significance and degree of freedom, the calculated t-value must be less than the critical value $\left(t_{\text {critical }}=2.20, d f=\right.$ $11, p<0.05)$ for $95 \%$ and $\left(t_{\text {critical }}=3.12, d f=11, p<0.01\right)$ for $99 \%$. It was observed that the $t_{\text {cal }}<t_{\text {critical }}$ values for all the models under consideration. The $t-$ test shows that all models are significant at $95 \%$ and $99 \%$ confidence levels. However, the model, equation 15a (existing model) has the lowest value with 0.0357 and is judged the best model, while the model, equation $15 \mathrm{c}$ (existing model) has the highest value with 1.8605. Based on the NSE the models, equation $15 \mathrm{f}$ (existing model) and equation 15g (existing model) has the highest value with $97.6416 \%$ and are judged the best models while the model, equation 15c (existing model) has the lowest value with $96.9127 \%$. Based on the IA the model, equation 15d (existing model) has the highest value with $99.4010 \%$ and is judged the best model, while the model equation 15c (existing model) has the lowest value with $99.1466 \%$.

The ranking of the existing and author's model $\{$ Table 5B)\} was done based on the validation of the models $\{$ Table $5 \mathrm{~A})\}$. The total ranks acquired by the different models were in the range 20 to 61 . Based on the overall results for the sunshine based models for Sokoto, the model, equation $15 \mathrm{j}$ (author's model) is reported as the best and therefore most suitable for estimating global solar radiation in this location as compared to other evaluated sunshine based models. The model, equation $15 \mathrm{f}$ (existing model) was ranked $2^{\text {nd }}$ most suitable model.

The $1^{\text {st }}$ order Ångström type model results obtained for Sokoto in this study were compared to that carried out by Abdullahi and Sharafa [34]. The model equation with its empirical constants is given in equation 15a while the empirical constants given by Abdullahi and Sharafa [34] are 0.4785 and 0.2465.In this study the MBE, RMSE, MPE, and $\mathrm{R}^{2}$ were found to be $0.0093 \mathrm{MJm}^{-2} \mathrm{day}^{-1}, 0.8645 \%$, $0.1954 \%$ and $83.6 \%$ respectively while the MBE, RMSE and $\mathrm{R}^{2}$ given by Abdullahi and Sharafa (2017) are $0.2990 \%, 1.4324 \%$ and $63.0 \%$. In another study Argungu and Dabai [13] obtained empirical constants of 0.0988 and 0.7875 withMBE, RMSE, MPE and R ${ }^{2}$ as $0.037 \mathrm{MJm}^{-2} \mathrm{day}^{-1}, 1.512 \mathrm{MJm}^{-2} \mathrm{day}^{-1},-0.593 \%$ and $32.15 \%$. Thus, this is evident that the model in this study performs better than their model based on the statistical test result. However, the model, equation $15 \mathrm{r}$ (author's model) is reported as the best and therefore most suitable for estimating global solar radiation in this location as compared to other evaluated sunshine based models. 
Fig. 1A shows the comparison between the measured and estimated global solar radiation for Sokoto based on sunshine models. It is obvious that the estimated models underestimated the measured global solar radiation in the months from January to May and overestimated the measured global solar radiation in the months of June, July and September. The figure revealed that the model (Equation 15c) underestimated the measured and other estimated models in the months from January to May, August and from October to December; the model (Equation 15d) overestimated the measured and other estimated models in the months of June, July, September and October. In general, it can be seen from the figure that a good correlation existed between the measured and the models (Equation $15 \mathrm{f}$ and $15 \mathrm{j})$ as compared to other evaluated models.

\subsection{Temperature based models for Sokoto}

The evaluated regression equations for the existing temperature based models for Sokoto based on Table 3 are

$$
\begin{aligned}
\frac{H}{H_{0}} & =-0.0764+0.271 \ln \Delta T \\
\frac{H}{H_{0}} & =0.0454+0.159 \text { Sqrt } \Delta T \\
\frac{H}{H_{0}} & =0.351+0.241 \frac{\Delta T}{S_{0}}
\end{aligned}
$$

The evaluated regression equation for the authors proposed temperature based models for Sokoto based on Table 4 is

$$
\frac{H}{H_{0}}=0.595\left[\left(\frac{\Delta T}{S_{0}}\right)\right]^{0.407}
$$

\begin{tabular}{|c|c|c|c|c|c|c|c|c|}
\hline Models & $\mathrm{R}^{2}$ & MBE & RMSE & MPE & $\mathrm{t}$ & NSE & IA & Total Rank \\
\hline Eqn.16a & 4 & 2 & 3 & 1 & 2 & 3 & 4 & 19 \\
\hline Eqn. $16 b$ & 3 & 4 & 4 & 4 & 4 & 4 & 3 & 26 \\
\hline Eqn.16c & 2 & 3 & 2 & 3 & 3 & 2 & 2 & 17 \\
\hline Author's Models & $\mathrm{R}^{2}$ & MBE & RMSE & MPE & $\mathrm{t}$ & NSE & IA & Total Rank \\
\hline Eqn.16d & 1 & 1 & 1 & 2 & 1 & 1 & 1 & 8 \\
\hline
\end{tabular}

Table 6: A) Validation of the Temperature Based Models for Sokoto under Different Statistical Test

\begin{tabular}{lllllll}
\multicolumn{7}{c}{ Table 6: A) } \\
\hline Models & $\mathrm{R}^{2}$ & MBE & RMSE & MPE & t & NSE \\
\hline Eqn.16a & 87.6 & 0.0156 & 0.7402 & -0.0155 & 0.0698 & 98.1252 \\
Eqn.16b & 87.8 & 0.0916 & 0.743 & -0.3831 & 0.4119 & 98.1112 \\
Eqn.16c & 93.2 & 0.0266 & 0.5435 & -0.1341 & 0.1623 & 98.9893 \\
Author's Model & $\mathrm{R}^{2}$ & MBE & RMSE & MPE & t & 99.53915 \\
Eqn.16d & 93.8 & -0.0069 & 0.5269 & 0.0452 & 0.0433 & NSE \\
\hline
\end{tabular}

Table 6: B) Ranking of the Evaluated Temperature Based Models for Sokoto as Per Statistical Test

Table 6A) and 6B) gives the summary of the various statistical tests adopted and ranking of the temperature based models for Sokoto. Based on the $\mathrm{R}^{2}$ the model, equation 16d (author's model) has the highest value with $93.8 \%$ and is judged the best model, while the model, equation 16a (existing model) has the lowest value with $87.6 \%$. Based on the MBE, the model, equation 16d (author's model) has the lowest value with underestimation of $0.0069 \mathrm{MJm}^{-2} \mathrm{day}^{-1}$ in the estimated value and is judged the best model, while the model, equation $16 \mathrm{~b}$ (existing model) has the highest value with overestimation of $0.0916 \mathrm{MJm}^{-2} \mathrm{day}^{-1}$ in the estimated value. Based on the RMSE the model, equation 16d author's model) has the lowest value with $0.5269 \mathrm{MJm}^{-2} \mathrm{day}^{-1}$ and is judged the best model, while the model, equation $16 \mathrm{~b}$ (existing model) has the highest value with $0.7430 \mathrm{MJm}^{-2} \mathrm{day}^{-1}$. Based on the MPE, despite the observed overestimation and underestimation exhibited by some of the existing and researcher's models they all fall within the acceptable range ( $M P E \leq$ $\pm 10 \%$ ) with the model, equation 16 a (existing model) having the lowest value with underestimation of $0.0155 \%$ in the estimated value and is judged the best model, while the model, equation $16 \mathrm{~b}$ (existing model) has the highest value with underestimation of $0.3831 \%$ in the estimated value. The study site was statistically tested at the $(1-\alpha)$ confidence levels of significance of $95 \%$ and $99 \%$. For the critical t-value, i.e., at $\alpha$ level of significance and degree of freedom, the calculated t-value must be less than the critical value $\left(t_{c r i t i c a l}=\right.$ $2.20, d f=11, p<0.05)$ for $95 \%$ and $\left(t_{\text {critical }}=3.12, d f=11, p<0.01\right)$ for $99 \%$. It was observed that the $t_{\text {cal }}<t_{\text {critical }}$ values for all the models under consideration. The $t-$ test shows that all models are significant at $95 \%$ and $99 \%$ confidence levels. However, the model, equation 16d (author's model) has the lowest value with 0.0433 and is judged the best model, while the model, equation $16 \mathrm{~b}$ (existing model) has the highest value with 0.4119. Based on the NSE the model, equation 16d (author's model) has the highest value with 99.0500 \% and is judged the best models, while the model, equation $16 \mathrm{~b}$ (existing model) has the lowest value with $98.1112 \%$. Based on the IA the model, equation 16d (author's model) has the highest value with $99.7634 \%$ and is judged the best models, while the model, equation 16 a (existing model) has the lowest value with $99.5392 \%$.

The ranking of the existing and author's models \{Table 6B)\} was done based on the validation of the models $\{$ Table $6 \mathrm{~A})\}$. The total ranks acquired by the different models were in the range 8 to 26 . Based on the overall results for the temperature based models for Sokoto, the model, equation 16d (author's model) is reported as the best and therefore most suitable for estimating global solar radiation in this location as compared to other evaluated temperature based models. The model, equation 16c (existing model) was ranked $2^{\text {nd }}$ most suitable model.

Fig. 1B shows the comparison between the measured and estimated global solar radiation for Sokoto based on temperature models. It is obvious that the estimated models underestimated the measured global solar radiation in the months of January, September, October and November and overestimated the measured global solar radiation in the months from February to July. The figure revealed that the model (Equation 16b) overestimated the measured and other estimated models in its estimated values in the months of March and April. Similarly, is the model (Equation 16c) in the months of February, August and December. The model (Equation 16a) underestimation the measured and other estimated models in the month of January, August, September, November and December. The figure depicts that all 
the evaluated models revealed a good correlation with the measured as there are no considerable deviation. However, it can be seen that a good correlation existed between the measured and the models (Equation 16c and 16d) as compared to other evaluated models.

(A)

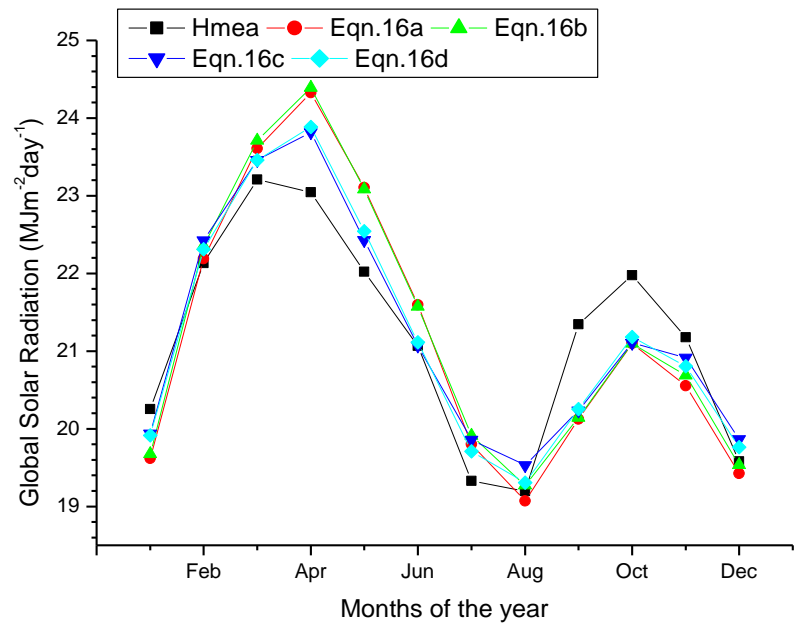

(B)

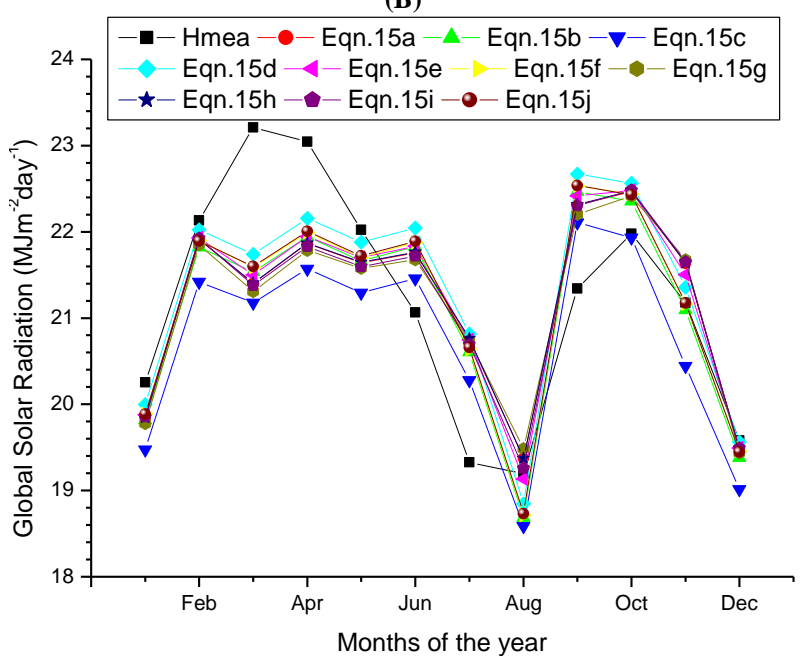

Fig. 1: Comparison between Measured and Estimated Global Solar Radiation for Sokoto (A) Sunshine Based Models (B) Temperature Based Models.

Table 7: Comparison/Ranking Between the Recommended Sunshine Based Models (SBM) and Temperature Based Models (TBM) for Sokoto

\begin{tabular}{llllllllllll}
\hline Sahelian & Models & Equation & $\mathrm{R}^{2}$ & MBE & RMSE & MPE & t & NSE & IA & Total & Best \\
\multirow{2}{*}{ Sokoto } & SBM & Eqn.15j & 2 & 2 & 2 & 1 & 2 & 2 & 2 & 13 & \multirow{2}{*}{ TBM } \\
& TBM & Eqn.16d & 1 & 1 & 1 & 2 & 1 & 1 & 1 & 8 & \\
\hline
\end{tabular}

Table 7 shows that the temperature based model is more appropriate for estimating global solar radiation in the location under investigation. However, when temperature data are not available the sunshine hours data can reliably estimate global solar radiation using the proposed sunshine based model. According to Ajayi et al. [35], models with regard to Nigeria do not include the latitude, their accuracy and applications were limited to the sites from which the models were developed. Thus, the insertion of latitude in our sunshine based model makes it to some extend site independent and able to take into custody the differences due to variation in geographical locations. This is in line with that reported by Ajayi et al. [35]. The developed model is synonymous to the Ogelma et al model, except for the introduction of the cosine of locations latitude. For the temperature based model, the developed model is synonymous to Garcia model except that, it has power without a constant term. The model is site dependent and it's in line with the study reported by Huashan et al. [36] in China.

\subsection{Multivariate regression models for Sokoto}

The regression equations for two variable correlations for Sokoto are

$$
\begin{aligned}
& \frac{H}{H_{0}}=0.364+0.411 \frac{S}{S_{0}}-0.000492 R F \\
& \frac{H}{H_{0}}=0.335+0.501 \frac{S}{S_{0}}-0.00133 R H \\
& \frac{H}{H_{0}}=0.816-0.00573 T_{\text {mean }}-0.000793 R F
\end{aligned}
$$




$$
\begin{aligned}
& \frac{H}{H_{0}}=1.04-0.000656 R F-0.0595 C C \\
& \frac{H}{H_{0}}=0.695-0.00557 W S-0.000825 R F
\end{aligned}
$$

where $\mathrm{T}_{\text {mean }}\left({ }^{0} \mathrm{C}\right)$, is the mean temperature, $\mathrm{S} / \mathrm{S}_{0}$ is the sunshine duration, $\mathrm{RF}$ is the rainfall in $\mathrm{mm}$, WS is the wind speed in $\mathrm{ms}^{-1}, \mathrm{CC}$ is the cloud cover and RH is the relative humidity in (\%).

Table 8: Validation of Multiple Linear Regression Models for Sokoto under Different Statistical Test for Two Variable Correlations

\begin{tabular}{lllllll}
\hline Models & $\mathrm{R}^{2}$ & MBE & RMSE & MPE & t & NSE \\
\hline Eqn.17a & 97.6 & 0.0117 & 0.3301 & -0.0323 & 0.1177 & 99.6272 \\
Eqn.17b & 97.4 & -0.0017 & 0.3397 & -0.037 & 0.0164 & 99.6052 \\
Eqn.17c & 96.3 & -0.0072 & 0.3671 & 0.0248 & 0.065 & 99.9074 \\
Eqn.17d & 93.1 & 0.0645 & 0.5205 & -0.2108 & 0.4138 & 99.9007 \\
Eqn.17e & 89.7 & 0.0238 & 0.667 & -0.0025 & 0.1185 & 99.0728 \\
\hline
\end{tabular}

Table 8 shows the summary of the various statistical tests performed on the two variable correlations for Sokoto, in order to ascertain the accuracies of the proposed models. Based on the $R^{2}$, the model (Equation 17a) has the highest value and is judged as the best model. Based on the MBE it was observed that the models (Equation 17a, 17d and 17e) indicate overestimation in the estimated values, while the models Equation (17b and 17c) indicate underestimation in the estimated values. However, the model (Equation 17b) has the lowest MBE value as compared with all the developed models and was returned as the best performing model. Based on the RMSE, the model (Equation 17a) has the lowest value as compared to all the developed models and was returned as the best performing model. Based on the MPE, all the models exhibits underestimation in the estimated values, except the model (Equation 17c) that exhibit overestimation in the estimated values, all the evaluated models perform better as they are all within the acceptable range of $-10 \%$ and $+10 \%$ with the model (Equation 17e) having the lowest value and was judged the best. The study location was statistically tested at the $(1-\alpha)$ confidence levels of significance of $95 \%$ and $99 \%$. The $t-$ test shows that all models are significant at $95 \%$ and $99 \%$ confidence levels with the model (Equation 17b) having the lowest value and was judged the best. Based on the NSE and IA the model (Equation 17a) has the highest value with $99.6272 \%$ and $99.9074 \%$ and is judged the best. It was observed that all the developed models are found suitable for predicting global solar radiation with higher accuracies.

Fig. 2A shows the comparison between the measured and the estimated global solar radiation for two variable correlations in Sokoto. It is obvious that the model (Equation 17e) underestimated the measured and other estimated models in the months of January, February and July and overestimated in its estimated values in the months of March to May. The model (Equation 17d) overestimated and underestimated the measured and other models in the months of October and December respectively. The model (Equation 17a) shows overestimation in the months of June and September and underestimation in the month of August as compared to the measured and other estimated models. The figure shows that all the estimated models overestimated the measured in the month of June. In general, all the estimated models exhibit good correlation with the measured.

The regression equations for three variable correlations for Sokoto are

$$
\begin{aligned}
\frac{H}{H_{0}} & =0.374+0.423 \frac{S}{S_{0}}-0.000278 R F-0.000698 R H \\
\frac{H}{H_{0}} & =0.437+0.455 \frac{S}{S_{0}}-0.00771 W S-0.00162 R H \\
\frac{H}{H_{0}} & =0.535+0.285 \frac{S}{S_{0}}-0.00288 T_{\text {mean }}-0.000584 R F \\
\frac{H}{H_{0}} & =1.04-0.00482 T_{\text {mean }}-0.000705 R F-0.0381 C C \\
\frac{H}{H_{0}} & =0.509+0.364 \frac{S}{S_{0}}-0.000487 R F-0.0173 C C
\end{aligned}
$$

Table 9: Validation of Multiple Linear Regression Models for Sokoto under Different Statistical Test for Three Variable Correlations

\begin{tabular}{llllllll}
\hline Models & $\mathrm{R}^{2}$ & MBE & RMSE & MPE & $\mathrm{t}$ & NSE & IA \\
\hline Eqn.18a & 98.8 & -0.0095 & 0.2412 & 0.0483 & 0.1313 & 99.8010 & 99.9502 \\
Eqn.18b & 98.7 & 0.0108 & 0.2400 & -0.0813 & 0.1500 & 99.8029 & 99.9506 \\
Eqn.18c & 98.7 & 0.0014 & 0.2349 & -0.0156 & 0.0199 & 99.8112 & 99.9528 \\
Eqn.18d & 97.9 & 0.0587 & 0.2765 & -0.2752 & 0.7210 & 99.7384 & 99.9353 \\
Eqn.18e & 97.9 & -0.0101 & 0.3053 & 0.0776 & 0.1096 & 99.6811 & 99.9205 \\
\hline
\end{tabular}

Table 9 shows the summary of the various statistical tests performed on the three variable correlations for Sokoto, in order to ascertain the accuracies of the proposed models. Based on the $R^{2}$, the model (Equation 18a) has the highest values and is judged as the best model. Based on the MBE it was observed that the models (Equation 18b, 18c and 18d) indicate overestimation in the estimated values, while the models (Equation 18a and 18e) indicate underestimation in the estimated values. However, the model (Equation 18c) has the lowest MBE value as compared with all the developed models and was returned as the best performing model. Based on the RMSE, the model (Equation 18c) has the lowest value as compared to all the developed models and was returned as the best performing model. Based on the MPE, the models (Equation 18b, 18c and 18d) exhibits underestimation in the estimated values while the models (Equation 18a and 18e) exhibit overestimation in the estimated values, all the evaluated models perform better as they are all within the acceptable range of $-10 \%$ and $+10 \%$ with the model (Equation 18c) having the lowest value and was judged the best. The study location was statistically tested at the $(1-\alpha)$ confidence levels of significance of $95 \%$ and $99 \%$. The $t-$ test shows that all models are significant at $95 \%$ and 99\% confidence levels with the model (Equation 18c) having the lowest value and was judged the best. Based on the NSE and IA the model (Equation 18c) has the highest value with $99.8112 \%$ and $99.9528 \%$ and is judged the best model. The developed models are found suitable for predicting global solar radiation with higher accuracies. 
Fig. 2B shows the comparison between the measured and the estimated global solar radiation for three variable correlations in Sokoto. It is obvious that the model (Equation 18d) overestimated the measured and other estimated models in the months of January, April and August and underestimated in its estimated values in the months of July and November. The model (Equation 18e) overestimated in the months of May, June, September and October and underestimated the measured and other models in the months of January August and December respectively. The figure shows that all the estimated models overestimated the measured in the month of April also in the month of May and June except for the model (Equation 18b). In general, all the estimated models exhibit good correlation with the measured.

The regression equations for four variable correlations for Sokoto are

$$
\begin{aligned}
& \frac{H}{H_{0}}=0.453+0.397 \frac{S}{S_{0}}-0.00648 W S-0.000234 R F-0.00104 R H \\
& \frac{H}{H_{0}}=0.711+0.225 \frac{S}{S_{0}}-0.00300 T_{\text {mean }}-0.000582 R F-0.0201 C C \\
& \frac{H}{H_{0}}=0.474+0.343 \frac{S}{S_{0}}-0.00173 T_{\text {mean }}-0.000409 R F-0.000453 R H \\
& \frac{H}{H_{0}}=0.515+0.378 \frac{S}{S_{0}}-0.000274 R F-0.0168 C C-0.000694 R H \\
& \frac{H}{H_{0}}=0.382+0.485 \frac{S}{S_{0}}-0.00766 W S+0.00116 T_{\text {mean }}-0.00158 R H
\end{aligned}
$$

Table 10: Validation of Multiple Linear Regression Models for Sokoto under Different Statistical Test for Four Variable Correlations

\begin{tabular}{llllllll}
\hline Models & $\mathrm{R}^{2}$ & MBE & RMSE & MPE & $\mathrm{t}$ & NSE & IA \\
\hline Eqn.19a & 99.7 & -0.0072 & 0.1244 & 0.0422 & 0.1936 & 99.9471 & 99.9868 \\
Eqn.19b & 99.0 & -0.0133 & 0.1978 & 0.0604 & 0.2234 & 99.8661 & 99.9664 \\
Eqn.19c & 99.0 & 0.0159 & 0.2104 & -0.0842 & 0.2518 & 99.8485 & 99.9622 \\
Eqn.19d & 99.0 & -0.0048 & 0.2110 & 0.0325 & 0.0756 & 99.8477 & 99.962 \\
Eqn.19e & 99.0 & 0.0253 & 0.2105 & -0.1269 & 0.4020 & 99.8484 & 99.9622 \\
\hline
\end{tabular}

Table 10 shows the summary of the various statistical tests performed on the four variable correlations for Sokoto, in order to ascertain the accuracies of the proposed models. Based on the $R^{2}$, the model (Equation 19a) has the highest values and is judged as the best model. Based on the MBE it was observed that the models (Equation 19a, 19b and 19d) indicate underestimation in the estimated values, while the models (Equation 19c and 19e) indicate overestimation in the estimated values. However, the model (Equation 19d) has the lowest MBE value as compared with all the developed models and was returned as the best performing model. Based on the RMSE, the model (Equation 19a) has the lowest value as compared to all the developed models and was returned as the best performing model. Based on the MPE, the models (Equation 19c and 19e) exhibits underestimation in the estimated values while the models (Equation 19a, 19b and 19d) exhibit overestimation in the estimated values, all the evaluated models perform better as they are all within the acceptable range of $-10 \%$ and $+10 \%$ with the model (Equation 19d) having the lowest value and was judged the best. The study location was statistically tested at the $(1-\alpha)$ confidence levels of significance of $95 \%$ and $99 \%$. The $t-$ test shows that all models are significant at $95 \%$ and 99\% confidence levels with the model (Equation 19d) having the lowest value and was judged the best. Based on the NSE and IA the model (Equation 19a) has the highest value with $99.9471 \%$ and $99.9868 \%$ and is judged the best model. It was observed that all the developed models are found suitable for predicting global solar radiation with higher accuracies.

Fig. 2C shows the comparison between the measured and the estimated global solar radiation for four variable correlations in Sokoto. It is obvious that the model (Equation 19e) overestimated the measured and other estimated models in the months of February, March, July and November and underestimated in its estimated values in the months of January, May and June. The model (Equation 19b) overestimated in the months of January, September and October and underestimated the measured and other models in the months of July and November respectively. The figure shows that all the estimated models overestimated the measured in the month of April also except for the model (Equation 19b) in the month of July. In general, all the estimated models exhibit good correlation with the measured. The regression equations for five variable correlations for Sokoto are

$$
\begin{aligned}
\frac{\mathrm{H}}{\mathrm{H}_{0}} & =0.515+0.345 \frac{\mathrm{s}}{\mathrm{S}_{0}}-0.00605 \mathrm{WS}+0.00116 \mathrm{~T}_{\text {mean }}-0.000325 \mathrm{RF}-0.000850 \mathrm{RH} \\
\frac{\mathrm{H}}{\mathrm{H}_{0}} & =0.484+0.387 \frac{\mathrm{s}}{\mathrm{S}_{0}}-0.00614 \mathrm{WS}-0.000236 \mathrm{RF}-0.00420 \mathrm{CC}-0.00102 \mathrm{RH} \\
\frac{\mathrm{H}}{\mathrm{H}_{0}} & =0.643+0.283 \frac{\mathrm{s}}{\mathrm{s}_{0}}-0.00193 \mathrm{~T}_{\text {mean }}-0.000419 \mathrm{RF}-0.0188 \mathrm{CC}-0.000420 \mathrm{RH}
\end{aligned}
$$

Table 11: Validation of Multiple Linear Regression Models for Sokoto under Different Statistical Test for Five Variable Correlations

\begin{tabular}{llllllll}
\hline Models & $\mathrm{R}^{2}$ & MBE & RMSE & MPE & $\mathrm{t}$ & NSE & IA \\
\hline Eqn.20a & 99.8 & 0.0187 & 0.1055 & -0.0889 & 0.5957 & 99.9619 & 99.9905 \\
Eqn.20b & 99.7 & -0.0123 & 0.1228 & 0.0676 & 0.333 & 99.9484 & 99.9871 \\
Eqn.20c & 99.3 & 0.0046 & 0.1705 & -0.0252 & 0.0903 & 99.9005 & 99.9751 \\
\hline
\end{tabular}

Table 11 shows the summary of the various statistical tests performed on the five variable correlations for Sokoto, in order to ascertain the accuracies of the proposed models. Based on the $\mathrm{R}^{2}$, the model (Equation 20a) has the highest values and is judged as the best model. Based on the MBE it was observed that the models (Equation 20a and 20c) indicate overestimation in the estimated values, while the model (Equation 20b) indicates underestimation in the estimated values. However, the model (Equation 20c) has the lowest MBE value as compared with all the developed models and was returned as the best performing model. Based on the RMSE, the model (Equation 20a) has the lowest value as compared to all the developed models and was returned as the best performing model. Based on the MPE, all 
the models exhibits underestimation in the estimated values, except the model (Equation 20b) that exhibit overestimation in the estimated values, all the evaluated models perform better as they are all within the acceptable range of $-10 \%$ and $+10 \%$ with the model (Equation 20c) having the lowest value and was judged the best. The study location was statistically tested at the $(1-\alpha)$ confidence levels of significance of $95 \%$ and $99 \%$. The $t$ - test shows that all models are significant at $95 \%$ and $99 \%$ confidence levels with the model (Equation 20c) having the lowest value and was judged the best while the model (Equation 20a) has the highest. Based on the NSE and IA the model (Equation 20a) has the highest value with $99.9619 \%$ and $99.9905 \%$ and is judged the best model. It was observed that all the developed models are found suitable for predicting global solar radiation with higher accuracies.

Fig. 2D shows the comparison between the measured and the estimated global solar radiation for five variable correlations in Sokoto. The figure shows that all the estimated models underestimated the measured in the months of March and August and overestimated the measured in the months of April and July.It is obvious that the model (Equation 20c) overestimated the measured and other estimated models in the months of January, February, May and June and underestimated in its estimated values in the months from August to December. The model (Equation 20a) overestimated the measured and other estimated models in the months of September and December. In general, all the estimated models exhibit good correlation with the measured.

The regression equations for six variable correlation for Sokoto is

$$
\frac{\mathrm{H}}{\mathrm{H}_{0}}=0.573+0.322 \frac{\mathrm{S}}{\mathrm{S}_{0}}-0.00544 \mathrm{WS}-0.00130 \mathrm{~T}_{\text {mean }}-0.000338 \mathrm{RF}-0.00697 \mathrm{CC}-0.000797 \mathrm{RH}
$$

Table 12: Validation of Multiple Linear Regression Models for Sokoto under Different Statistical Test for Six Variable Correlations

\begin{tabular}{llllllll}
\hline Models & $\mathrm{R}^{2}$ & MBE & RMSE & MPE & $\mathrm{t}$ & NSE & IA \\
\hline Eqn.21 & 99.8 & -0.0259 & 0.101 & 0.1232 & 0.88 & 99.9651 & 99.9912 \\
\hline
\end{tabular}

All the statistical test analysis for the six variable correlations shown on Table 12 shows high statistical significant relationship between the estimated and measured global solar radiation based on the six meteorological variables used in the study site. Therefore, could be used for predicting global solar radiation with higher accuracies as evaluation depends on the available combination of the six meteorological parameters based on the developed model.

Fig. 2E shows the comparison between the measured and the estimated global solar radiation for six variable correlation in Sokoto. The figure shows that there is no considerable deviation between the estimated model and the measured. Though, the estimated model underestimated the measured in the months of January, March, May, June, August, October, November and December and overestimated the measured in the months of February, April, July and September. In general, the estimated model exhibit good correlation with the measured.

(A)

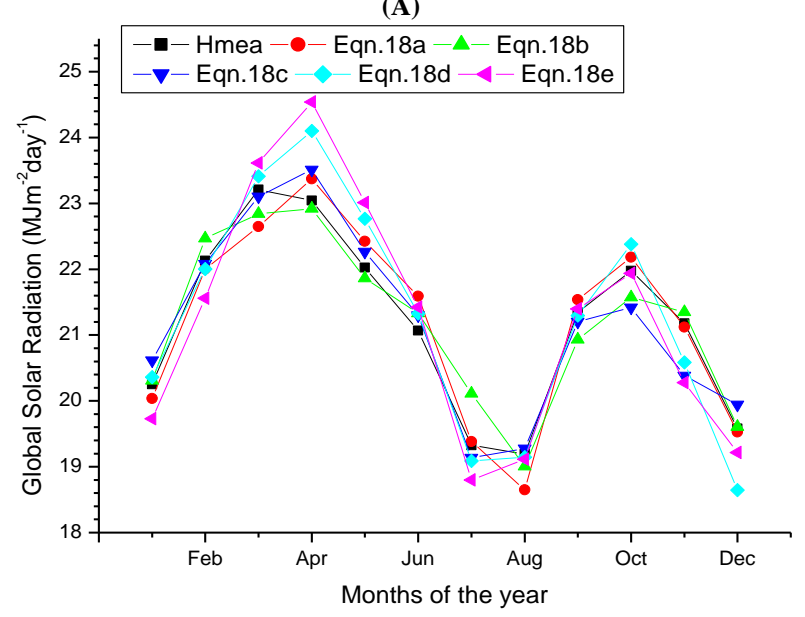

(B)

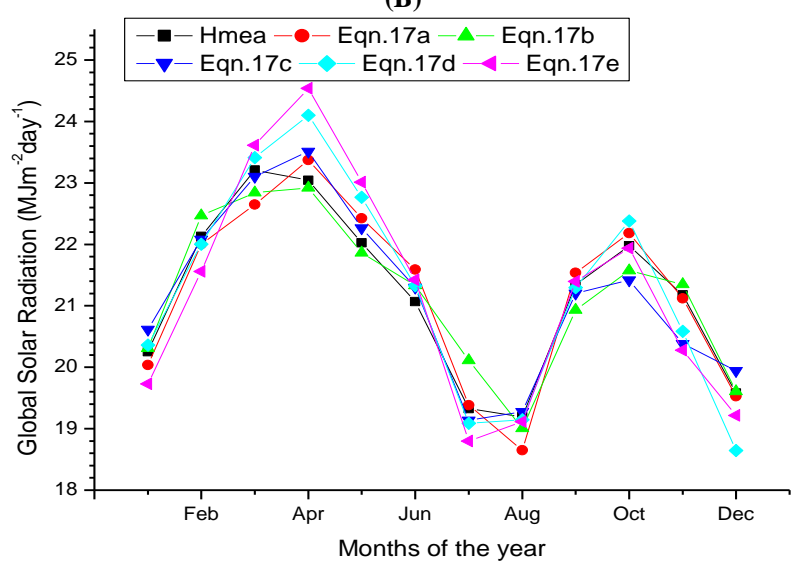



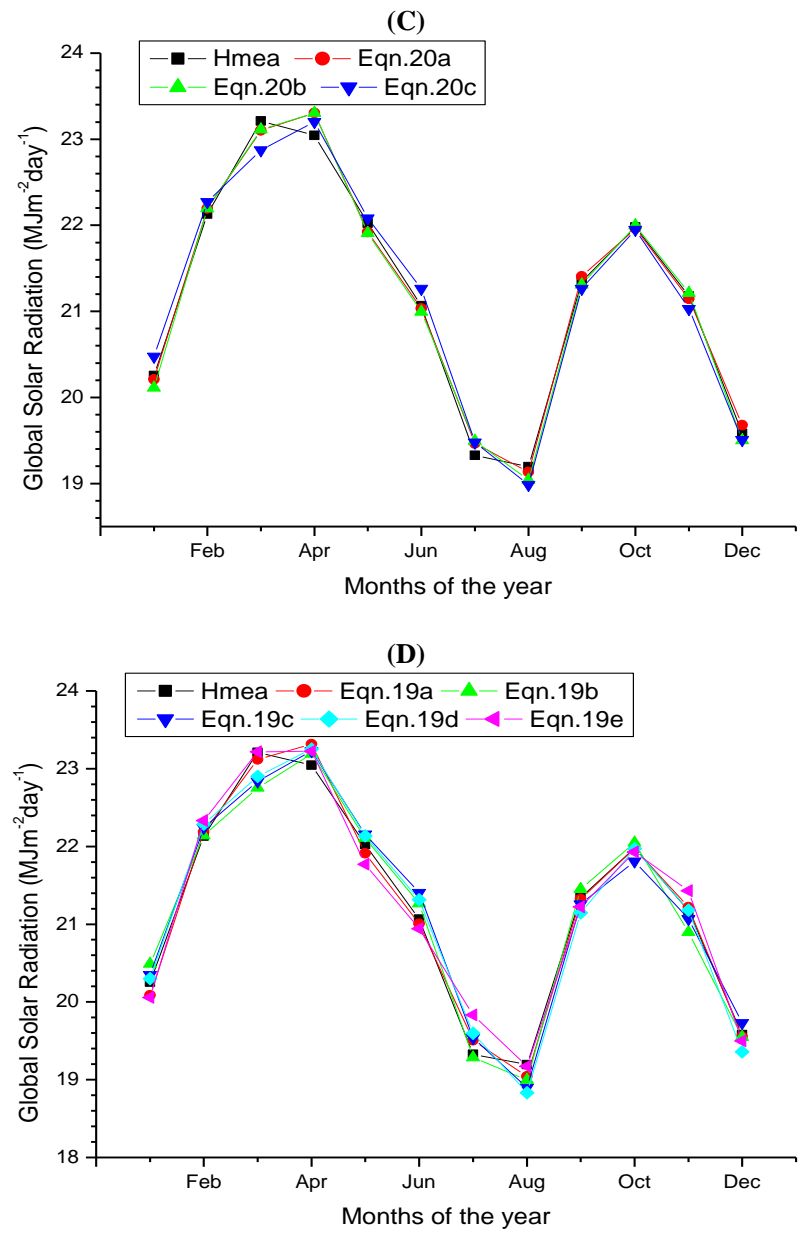

(E)

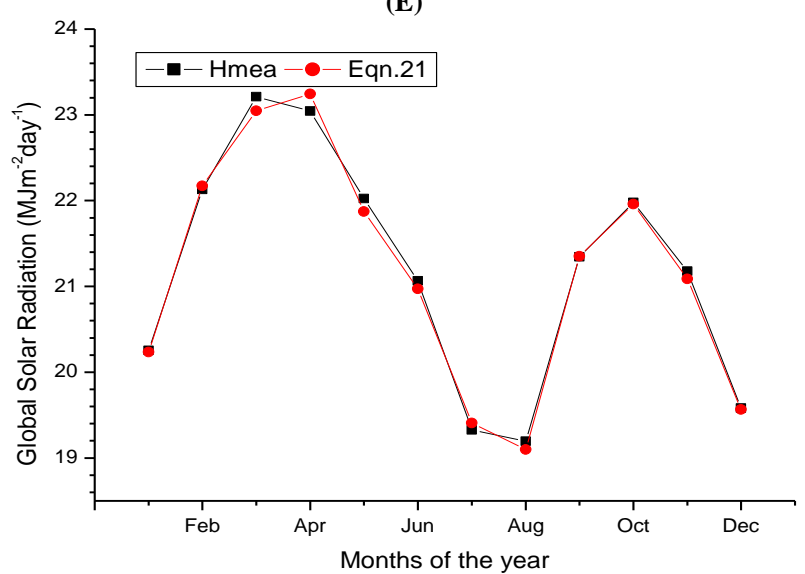

Fig. 2: Comparison between Measured and Estimated Global Solar Radiation for Sokoto (A) Two Variable Correlations (B) Three Variable Correlations (C) Four Variable Correlations (D) Five Variable Correlations (E) Six Variable Correlation.

\section{Conclusion}

A wide-ranging study was carried out to help in the selection of the most fitting and accurate models based on the statistical test indicators of coefficient of determination $\left(\mathrm{R}^{2}\right)$, Mean Bias Error (MBE), Root Mean Square Error (RMSE), Mean Percentage Error (MPE), $t$ test, Nash - Sutcliffe Equation (NSE) and Index of Agreement (IA) using meteorological parameters of measured monthly average daily global solar radiation, maximum and minimum temperatures, sunshine hours, rainfall, wind speed, cloud cover and relative humidity meteorological data during the period of thirty one years (1980-2010) for Sokoto located in the Sahelian region in Nigeria. The evaluated models are classified into three categories namely, sunshine, temperature and multivariate based. In each category, the most accurate models are identified and presented. A total of ten (10) sunshine based models were evaluated and compared out of which nine (9) are existing models and one newly developed author's model. A total of four (4) temperature based models were evaluated and compared, three (3) existing and one newly developed author's temperature based model. The results indicated that the modified author's newly developed sunshine and temperature based models produces more accurate global solar radiation estimates than the existing models examined for the studied location.

The evaluated existing Ångström type sunshine based model was found more suitable for estimating global solar radiation when compared to those available in literature from other studies. This may be attributed to the quality and quantities of the data used in this study 
as they met the World Meteorological Organization (WMO) standards. The correlation between the measured and evaluated models shows overestimation and underestimation in their evaluated values in some months with the temperature based models been more correlated. The new temperature based model was found more appropriate for global solar radiation in the location when compared to the new sunshine based model. In general, all the developed multivariate regression models are found appropriate as evaluation relies on the obtainable combination of the meteorological parameters based on two to six variable correlation and they all exhibited good correlation with the measured. It is believed that this study has addressed the issue of estimating global solar radiation with higher accuracy for Sokoto, Nigeria.

\section{Acknowledgement}

The authors are grateful to the management and staff of the Nigerian Meteorological Agency (NIMET), Oshodi, Lagos for providing all the necessary data used in this present study. The anonymous reviewers are also appreciated.

\section{Funding}

This research did not receive any specific grant from funding agencies in the public, commercial, or not-for-profit sectors.

\section{References}

[1] E. O. Ogolo, Evaluating the performance of some predictive models for estimating global solar radiation across varying climatic conditions in Nigeria. Indian Journal of Radio \& space Physics, 39 (2010) 121-131.

[2] B. Viorel, Modeling solar radiation at the earth's surface: Recent advances. Springer. (2008)

[3] M. S. Dresselhaus, I. L. Thomas, Alternative Energy Technologies. Nature, 4146861 (2001) 332-337. https://doi.org/10.1038/35104599.

[4] A. Kassem, A. Aboukarima, N. El Ashmawy, Development of Neural Network Model to Estimate Hourly Total and Diffuse Solar Radiation on Horizontal Surface at Alexandria City (Egypt), Journal of Applied Sciences Research, 5, 11 (2009) 2006-2015.

[5] M. Alam, S. Saha, M. Chowdhury, M. Rahman, Simulation of Solar Radiation System, Am. J. Appl. Sci, 2,4 (2005) 751 758.https://doi.org/10.3844/ajassp.2005.751.758.

[6] A. Al-Salihi, M. Kadum, A. Mohammed, Estimation of Global Solar Radiation on Horizontal Surface Using Meteorological Measurement for different Cities in Iraq, Asian J. Sci. Res, 3, 4 (2010) 240 - 248.https://doi.org/10.3923/ajsr.2010.240.248

[7] A. Ångström, Solar and terrestrial radiation. Quarterly Journal of the Royal Meteorological society, 50 (1924) 121-125.

[8] J. K. Page, The estimation of monthly mean values of daily total short - wave radiation on vertical and inclined surfaces from sunshine records for latitude $40^{\circ} \mathrm{N}-40^{\circ} \mathrm{S}$. Proceeding of the UN Conference on New Sources of Energy, Rome, 4 (1964) $378-390$.

[9] B. I. Tijjani, Comparison between first and second order Ångström type models for sunshine hours at Katisna, Nigeria. Bayero Journal of Pure and Applied Sciences, 4 (2011) 24-27. https://doi.org/10.4314/bajopas.v4i2.5.

[10] A. Muhammad, T. H. Darma, Estimation of Global Solar Radiation for Kano State Nigeria Based on Meteorological Data, IOSR Journal of Applied Physics, 6, 1 (2014) 19 - 23.https://doi.org/10.9790/4861-06611923.

[11] G. I. Olatona, A. E. Adeleke, Estimation of Solar Radiation over Ibadan from Routine Meteorological Parameters, The International Journal Of Engineering And Science (IJES), 4, 3 (2015) $44-51$.

[12] S. G. Abdu, A. S. Abdullateef, Empirical Model for the Estimation of Monthly Global Solar Radiation in Zaria, Nigeria. International Journal of Physics and Mathematical Sciences, 6, 4 (2016) $57-62$.

[13] G. M. Argungu, K. Dabai, Application of Linear Models for Estimation of Global Solar Radiation using Available Meteorological Parameters for Sokoto, Nigeria. International Journal of Advances in Scientific Research and Engineering (ijasre), 3, 11 (2017) 76 - 83.

[14] D. N. Girma, Estimation of Monthly Average Daily Solar Radiation from Meteorological Parameters: Sunshine Hours and Measured Temperature in Tepi, Ethiopia. International Journal of Energy and Environmental Science. Vol. 3, No. 1 (2018) 1926.https://doi.org/10.11648/j.ijees.20180301.12.

[15] WMO, A Note on Climatological Normal. Technical Note. World Meteorological Organization, Geneva, Switzerland. (1967).

[16] O. S. Ojo, B. Adeyemi, Estimation of Solar Radiation using Air Temperature and Geographical Coordinate over Nigeria, The Pacific Journal of Science and Technology, 15, 2 (2014) $78-88$.

[17] M. Iqbal, An introduction to solar radiation, first ed. Academic Press, New York. (1983)

[18] S. Zekai, Solar energy fundamentals and modeling techniques: atmosphere, Environment, climate change and renewable energy, first ed. Springer, London. (2008)

[19] E. O. Falayi, A. B. Rabiu, R. O. Teliat, Correlations to estimate monthly mean of daily diffuse solar radiation in some selected cities in Nigeria, Pelagia Research Library, 2, 4 (2011) 480-490.

[20] J.A. Prescott, Transactions of the Royal Society of Australia 48 (1940) 114-8.

[21] H. Ogelman, A. Ecevit, E. Tasdemiroglu, A new method for estimating solar radiation from bright sunshine data, Solar Energy, 33 (1984) $619-$ 25.https://doi.org/10.1016/0038-092X(84)90018-5.

[22] T. D. M. A. Samuel, Estimation of global radiation for Sri Lanka, Solar Energy, 47 (1991) 333-337.https://doi.org/10.1016/0038-092X(91)90026-S

[23] F. J. Newland, A study of solar radiation models for the coastal regions of South China, Solar Energy, 31 (1988) 227 235.https://doi.org/10.1016/0038-092X(89)90022-4.

[24] D. B. Ampratwum, A. S. S Dorvlo, Estimation of solar radiation from the number sunshine hours, Applied Energy, 63 (1999) 161 - 167. https://doi.org/10.1016/S0306-2619(99)00025-2.

[25] K. Bakirci, Correlations for estimation of daily global solar radiation with hours of bright sunshine in Turkey, Energy, 34 (2009) 485 501.https://doi.org/10.1016/j.energy.2009.02.005.

[26] J. Almorox, C. Hontoria, Global solar radiation estimation using sunshine duration in Spain, Energy Conversion and Management, 45 (2004) 1529 - 1535.https://doi.org/10.1016/j.enconman.2003.08.022.

[27] A. Louche, G. Notton, P. Poggi, G. Simonnot, Correlations for direct and Global horizontal irradiation on a French Mediterranean site, Solar Energy, 46 (1991) 261 - 6.https://doi.org/10.1016/0038-092X(91)90072-5.

[28] R. Chen, K. Ersi, J. Yang, S. Lu, W. Zhao, Validation of five global radiation Models with measured daily data in China. Energy Conversion and Management, 45 (2004) 1759-1769.https://doi.org/10.1016/j.enconman.2003.09.019.

[29] G. Hargreaves, Z. Samani, Estimating potential evapotranspiration. Journal of Irrigation and Drainage Engineering. ASCE, 108 (1982) 225-230.

[30] J. V. Garcia, PrincipiosF'isicos de la Climatolog'ia. Ediciones UNALM (Universidad Nacional Agraria La Molina: Lima, Peru) (1994)

[31] A. El-Sebaii, A. Trabea, Estimation of Global Solar Radiation on Horizontal Surfaces Over Egypt, Egypt. J. Solids, 28, 1 (2005) $163-175$.

[32] P. R. Bevington, Data reduction and error analysis for the physical sciences, first ed. McGraw Hill Book Co., New York (1969)

[33] H. O. Merges, C. Ertekin, M. H. Sonmete, Evaluation of global solar radiation Models for Konya, Turkey. Energy Conversion and Management, 47 (2006) 3149-3173.https://doi.org/10.1016/j.enconman.2006.02.015. 
[34] M. B. Abdullahi, S. B. Sharafa, Multivariable Empirical Equation for Estimation of Global Solar Radiation in Sokoto Nigeria. ATBU, Journal of Science, Technology \& Education (JOSTE);Vol. 5, 3 (2017) 187 - 192

[35] O. O. Ajayi, O. D. Ohijeagbon, C. E Nwadialo, O. Olasope, New Model to Estimate Daily Global Solar Radiation over Nigeria. Sustainable Energy Technologies and Assessments, 5 (2014) 28 - 36. https://doi.org/10.1016/j.seta.2013.11.001.

[36] L. Huashan, C. Fei, W. Xianlong, M. Weibin, A Temperature-Based Model for Estimating Monthly Average Daily Global Solar Radiation in China. Hindawi Publishing Corporation. The Scientific World Journal, Volume 2014 (2014) 1 - 9. https://doi.org/10.1155/2014/128754. 